\title{
CCDC26 $\frac{1}{\mathrm{KIT}}$

Long noncoding RNA, CCDC26, controls myeloid leukemia cell growth through regulation of KIT expression

Hirano et al. 


\title{
Long noncoding RNA, CCDC26, controls myeloid leukemia cell growth through regulation of KIT expression
}

\author{
Tetsuo Hirano ${ }^{1 *}$, Ryoko Yoshikawa ${ }^{1}$, Hironori Harada ${ }^{2}$, Yuka Harada ${ }^{2}$, Atsuhiko Ishida ${ }^{1}$ and Takeshi Yamazaki ${ }^{1}$
}

\begin{abstract}
Background: Accumulating evidence suggests that some long noncoding RNAs (IncRNAs) are involved in certain diseases, such as cancer. The IncRNA, CCDC26, is related to childhood acute myeloid leukemia (AML) because its copy number is altered in AML patients.
\end{abstract}

Results: We found that CCDC26 transcripts were abundant in the nuclear fraction of $\mathrm{K} 562$ human myeloid leukemia cells. To examine the function of CCDC26, gene knockdown (KD) was performed using short hairpin RNAs (shRNAs), and four KD clones, in which CCDC26 expression was suppressed to $1 \%$ of its normal level, were isolated. This down-regulation included suppression of CCDC26 intron-containing transcripts (the CCDC26 precursor mRNA), indicating that transcriptional gene suppression (TGS), not post-transcriptional suppression, was occurring. The shRNA targeting one of the two CCDC26 splice variants also suppressed the other splice variant, which is further evidence for TGS. Growth rates of KD clones were reduced compared with non-KD control cells in media containing normal or high serum concentrations. In contrast, enhanced growth rates in media containing much lower serum concentrations and increased survival periods after serum withdrawal were observed for KD clones. DNA microarray and quantitative polymerase chain reaction screening for differentially expressed genes between KD clones and non-KD control cells revealed significant up-regulation of the tyrosine kinase receptor, KIT, hyperactive mutations of which are often found in AML. Treatment of KD clones with ISCK03, a KIT-specific inhibitor, eliminated the increased survival of KD clones in the absence of serum.

Conclusions: We suggest that CCDC26 controls growth of myeloid leukemia cells through regulation of KIT expression. A KIT inhibitor might be an effective treatment against the forms of AML in which CCDC26 is altered.

Keywords: Long noncoding RNA, Myeloid leukemia cells, Cell survival, Receptor tyrosine kinase, shRNA-induced transcriptional gene suppression, Stem cell factor, Serum depletion

\section{Background}

Noncoding RNAs (ncRNAs) are usually transcribed by RNA polymerase II and have intrinsic functions without being translated into polypeptides [1-4]. MicroRNAs (miRNAs), are important ncRNAs of approximately $20 \mathrm{bp}$ that silence specific target genes [5-9], while long noncoding RNAs (lncRNAs) are between $200 \mathrm{bp}$ and several $\mathrm{kb}$ and have numerous roles in cellular functions

\footnotetext{
* Correspondence: thirano@hiroshima-u.ac.jp

'Domain of Life Sciences, Graduate School of Integrated Arts and Sciences, Hiroshima University, 1-7-1 Kagamiyama, Higashihiroshima, Hiroshima 739-8521, Japan

Full list of author information is available at the end of the article
}

and gene regulation [10]. However, apart from a few examples, the molecular mechanisms by which most lncRNAs function remain to be fully elucidated $[11,12]$. Accumulating evidence suggests that some lncRNAs are involved in diseases, such as cancer [13,14]; therefore, it is important to understand their roles to facilitate the search for new therapeutic targets and to design new diagnostic methods.

Acute myeloid leukemia (AML) is a disease characterized by mutations in a set of genes [15-17]. These genes can be divided into two classes. One class includes genes related to cell differentiation, HOXA9, AML1, MLL and RAR $\alpha$, and the other consists of genes related to proliferation or 
survival of cells and includes FLT3, ABL, RAS and KIT. Mutations in genes of both classes need to occur to give rise to AML [15,18]. Fusion of $B C R$ and $A B L(B C R / A B L)$ is well known to be sufficient to cause chronic myeloid leukemia (CML) [19]. However, acute blastic crisis of CML is often accompanied by mutation of genes that are also mutated in $A M L$, such as HOXA9 or AML1 [20,21]. Thus, hematopoietic tyrosine kinases, including FLT3, $A B L, R A S$ and KIT, seem to have a similar role in AML and CML [22]. Considering the importance of imatinib, an ABL tyrosine kinase inhibitor used in the treatment of $B C R / A B L$ positive $C M L$, inhibitors against other tyrosine kinases are likely to become increasingly important for the treatment of AML [19,23]. KIT is a receptor tyrosine kinase that is considered to have a role in AML because of its frequent up-regulation in patients. Expression of KIT in leukemia stem cells (LSCs) from pediatric AML patients who relapsed after chemotherapy was increased compared with that in patients who did not relapse [24].

The function of the lncRNA, CCDC26, is not known. There is no evidence for a functional CCDC26 protein; moreover, the hypothetical 109 amino acid protein encoded in its mRNA has no homology with known proteins [25]. Despite the ambiguous nature of CCDC26, several lines of evidence support a relationship of CCDC26 with tumors, including AML. Radtke and colleagues investigated copy number alterations (CNAs) in pediatric AML genomes and found that the most common CNA is a low burden increase of a region within the $C C D C 26$ locus [26]. Studies by ourselves and others have shown that part of or the entire $C C D C 26$ gene is often amplified in AML cells harboring aberrant double minute chromosomes [27-29]. Others suggest that sensitivity of AML cells to anticancer drugs, including retinoic acid, is lost with integration of retroviral DNA into the $C C D C 26$ locus [30]. Linkage of CCDC26 with tumors, including low-grade glioma, was also suggested by genome wide association studies [31].

In this paper, we demonstrate that knockdown of CCDC26 in CML-derived $\mathrm{K} 562$ cells results in transcriptionally-altered expression of several genes, including activation of KIT, and prolonged cell survival under low or no serum conditions. ISCK03, a KIT inhibitor, abolished this prolonged survival. These results provide evidence for a new role of $C C D C 26$ in myeloid leukemia through the regulation of a set of genes that includes KIT.

\section{Results}

Expression of CCDC26 in various leukemia cell lines

To investigate the spectrum of cells that express $C C D C 26$, the absolute number of RNA molecules in a cell was determined by quantitative polymerase chain reaction (PCR) in several representative leukemia and non-leukemia cancer cell lines. The results are summarized in Figure 1A. CCDC26 was expressed in cells derived from AML (HL-60, ML-1, 039/TSU, KG-1, GDM-1, SKNO-1), acute monocytic leukemia (THP-1) and CML (K562, Meg-01, KU-812, MYLR). Very low expression (estimated at one molecule per cell, taking into account loss of RNA during preparation from cells) was observed in megakaryoblastic cells derived from leukemia accompanied with Down's syndrome (CMK) and in monocytic leukemia cells derived from histiocytic lymphoma (U937). No expression was observed in T lymphocytic leukemia cells (Jurkat), Burkitt's lymphoma cells (Raji) or nonhematopoietic cells, including U251MG (astrocytoma) and HeLa (cervical cancer) cells. These data indicate that expression of CCDC26 is strictly limited to myeloid cell lines of hematopoietic origin. Among them, the strongest expression of CCDC26 was observed in the AML cell line, HL-60. HL-60 cells, however, have a recombination upstream of $C C D C 26$ exon 4 and exons 1 to 3 of the gene are amplified on a double minute chromosome, which is an aberrant ring structure consisting of at least six discontinuous regions spanning $440 \mathrm{Mb}$ of $8 \mathrm{q} 24$. This region contains several genes, including CCDC26 and $M Y C$, and several abnormal transcripts, one of which involves $C C D C 26$ exons fused to other unrelated sequences, have been detected [27]. To avoid influence from such a complicated abnormal structure, we choose the K562 cell line, not HL-60, for further detailed analysis because $C C D C 26$ is also strongly expressed in this cell line and has no rearrangement in the vicinity of the $C C D C 26$ locus on $8 \mathrm{q} 24$.

\section{Different transcripts are generated from the CCDC26 locus}

K562 is a representative hematopoietic cell line, for which extensive biological information is archived in the Encyclopedia of DNA elements database [32]. According to information in the database, there are several transcriptional hot sites in CCDC26, including THS1 and THS2, as indicated in Figure 1B, where transcripts accumulate within introns outside of the known exons. In addition, there is a region designated hAK015428 showing a significant level of transcript in the $5^{\prime}$ region upstream of the first exon (Figure 1B). This region is conserved with the mouse ncRNA, AK015428 (Genbank accession number: AK015428). Indeed, we observed significant numbers of THS1, THS2 and hAK015428 transcripts (Figure 1C). hAK015428 was concentrated in the polyA $^{+}$fraction and its transcription was in the same direction as that of CCDC26; therefore, it seems to be an independent lncRNA (Additional file 1: Figure S1A and our unpublished data). We observed accumulation of CCDC26 and hAK015428 transcripts in isolated 
A

RNA Molecules/Cell

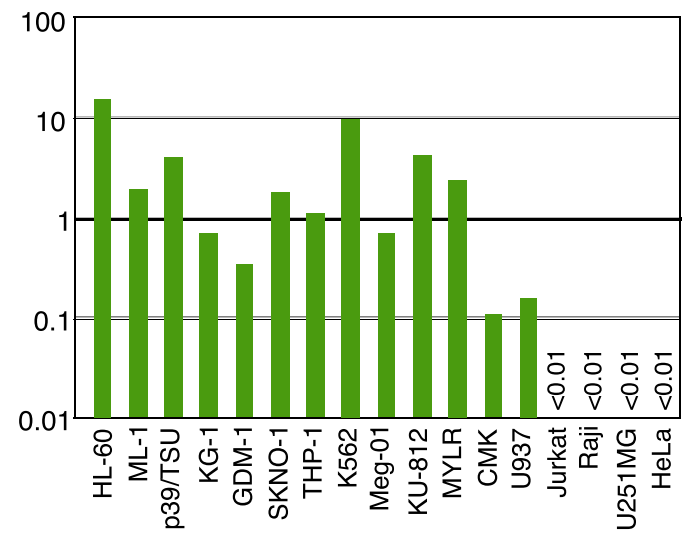

B

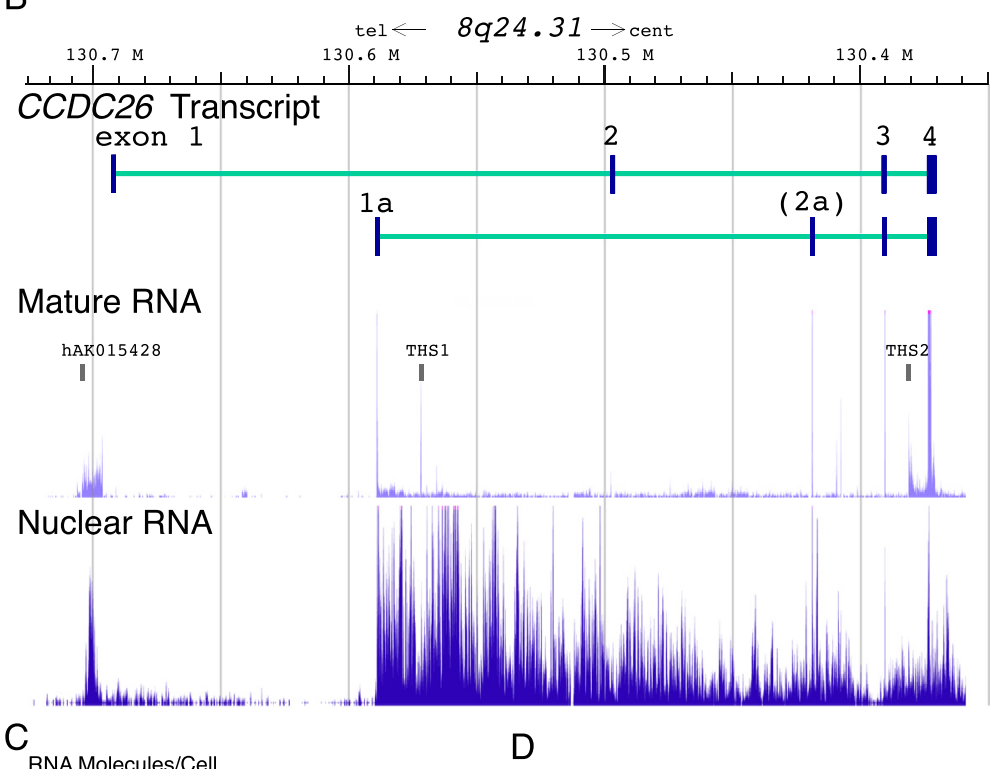

RNA Molecules/Cell

Relative RNA expression (fold)
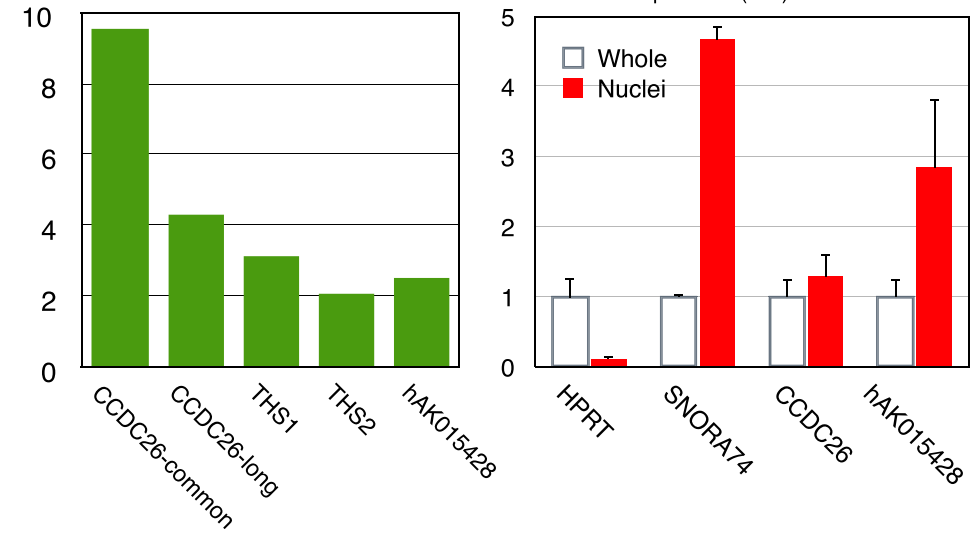

Figure 1 (See legend on next page.) 
(See figure on previous page.)

Figure 1 Expression of CCDC26 ncRNA. A: Estimated absolute number of CCDC26 mRNA molecules per cell in representative hematopoietic and nonhematopoietic cell lines, shown in the log scale. The absolute number of mRNA molecules per K562 cell of HPRT1, a house keeping gene, and $B C R / A B L$, an oncogene expressed in $K 562$ cells, was measured as $21+/-5$ and 45+/14, respectively. B: A map of human chromosome 8q24,

showing the location of the CCDC26 mRNA long and short variants (Genbank accession numbers: NR_130918 and NR_130917, respectively), other minor variants (NR_130919 and NR_130920) containing exon 2A, transcripts including hAK015428, transcriptional hot site 1 (THS1) and THS2, and scores of nuclear and whole cell transcripts in K562 cells. These scores are reprinted from the Human Feb. 2009 (GRCh37/hg19) assembly of the UCSC Genome Browser (http://genome.ucsc.edu/). C: Estimated absolute number of CCDC26, intron THS1, THS2 and hAK015428 transcripts in a K562 cell. D: Quantification of RNA in isolated nuclei and whole cells by quantitative PCR. For each assay, the same amount of RNA was used to synthesize cDNA. The value for HPRT in whole cell RNA was used as a standard. SNORA74, a snoRNA strictly located in nuclei, was used as a control for purity of the nuclear fraction.

nuclei of K562 cells (Figure 1D and Additional file 1: Figure S1A), suggesting a nuclear function.

\section{Repression of CCDC26 with short-hairpin knockdown vectors}

The function of CCDC26 was studied by constitutive knockdown using pGER, a short hairpin RNA (shRNA) expression plasmid (Additional file 2: Figure S2A) modified from GeneEraser pGE-1. We designed two shRNAs (sh-1250-1278 and sh-1440-1468) to knock down both the long and short variants of CCDC26 and two additional shRNAs (sh-331-359 and sh-279-307) to target only the long variant (Figure $2 \mathrm{~A}$ ). Figure $2 \mathrm{~B}$ shows the results of screening clones for shRNA suppression of CCDC26 (details of results for all clones are shown in Additional file 2: Figure S2B). Although CCDC26 suppression failed in most isolated clones, CCDC26 was suppressed in five clones $(22 \mathrm{~B} 11,32 \mathrm{H} 8,3-4,3 \mathrm{D} 1$ and 32E3) to levels of less than $2 \%$ of that in nontransfected K562 cells. After a second screen, we chose four clones (22B11, 32H8, 3-4 and 3D1) for further analysis in which expression of CCDC26 was repressed to levels of less than $1 \%$ of that in control cells (Figure 3C). Clone $32 \mathrm{E} 3$ was omitted because the level of CCDC26 expression was greater than $1 \%$ of that in control cells.

Transcriptional silencing of CCDC26 in knockdown clones Only one of the two transcript variants (the long variant) was targeted in clones 3-4 and 3D1; however, we observed total knockdown of all CCDC26 expression. To confirm this observation, we used additional primer sets and we detected that each $C C D C 26$ mRNA variant was knocked down with similar efficiency. As shown in Figure 1B, there are transcriptionally active sites in CCDC26 introns. We tested expression from these sites and found that they were also silenced, except for THS2 in knockdown (KD) clone 32H8 (Figure 3B). We also tested the expression of several genes in the vicinity of the CCDC26 locus (chromosome 8 location; 128,750,000-130,800,000) (Figure 3A). We found efficient silencing of $L O C 728724$, a gene independent from CCDC26, in all $\mathrm{KD}$ clones and partial silencing of GSDMC in clones 3-4 and 3D1. However, PVT1 and MYC were not significantly repressed (Figure 3B). Suppression of GSDMC in clones $3-4$ and 3D1 was partially prevented by treatment with $1.0 \mu \mathrm{M}$ trichostatin A (TSA), an inhibitor of histone deacetylase, and 1.0 $\mu \mathrm{M}$ 5-aza-2' -deoxycytidine (AzdC), an inhibitor of DNA methyltransferase (DNMT) (Figure $3 \mathrm{C}$ ), indicating that the silencing of these genes was mediated, at least in part, by epigenetic mechanisms. In contrast, suppression of $C C D C 26$ was not prevented by treatment with TSA and AzdC (Figure 3C).

\section{CCDC26 knockdown cells grow slowly in high concentrations of serum and show prolonged survival under serum depletion}

Proliferation of $\mathrm{K} 562$ cell lines in medium containing $15 \%$ fetal bovine serum (FBS) and $0.1 \%$ FBS was measured by counting live cells, as determined by trypan blue exclusion. Nontransformed and vector-transformed K562 cells proliferate rapidly with a doubling time of less than 12 hours, whereas KD clones showed prolonged doubling times (approximately 20 hours) (Figure 4A). In media containing 5-10\% FBS, similar differences in growth rate between non-KD and KD cells were observed (data not shown). However, more live KD cells were observed compared with non-KD cells after culture for 72 hours under serum starvation conditions $(0.1 \%$ FBS) (Figure 4B). We detected no significant morphological differences or altered expression of $\beta$-globin (a differentiation state marker for K562 cells) between KD clones and non-KD clones indicating no significant difference in the differentiation state of the clones (data not shown).

Less than $10 \%$ of non-KD and KD cells died when grown in medium containing high (5\% or more) concentrations of FBS up to a density of $1.5 \times 10^{6}$ cells $/ \mathrm{ml}$ (data not shown). In contrast, a high number of dead cells was observed under low serum conditions after serum starvation for 72 hours or more. Dead cells, as assessed by propidium iodide (PI) uptake, were counted by flow cytometry (FACS) analysis (Figure 4C-F). Significantly fewer dead cells were observed in KD clones compared with non-KD clones at 72 and 96 hours after serum depletion (Figure $4 \mathrm{C}$ and E). Figure $4 \mathrm{D}$ and F show FACS analysis examples of cells 72 and 96 hours after serum 


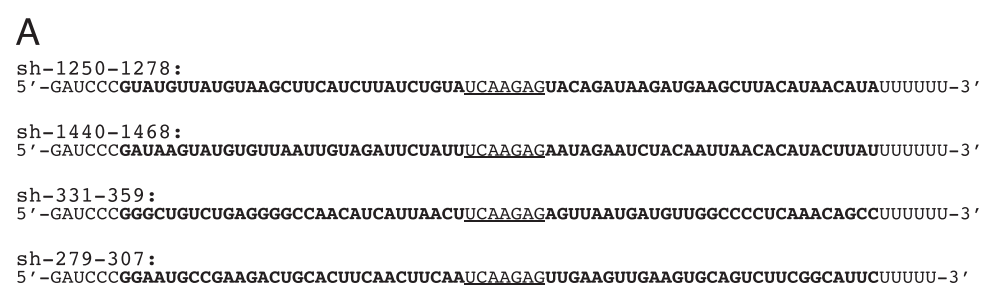

B

\begin{tabular}{|c|c|c|c|}
\hline shRNA & Target & Analysed & $K D<2 \%$ \\
\hline sh-1250-1278 & long and short & 35 & 22B 11 \\
\hline sh-1440-1468 & long and short & 44 & $32 \mathrm{E} 3,32 \mathrm{H} 8$ \\
\hline sh-331-359 & only long & 27 & $3-4,3 D 1$ \\
\hline sh-279-307 & only long & 32 & - \\
\hline
\end{tabular}

C

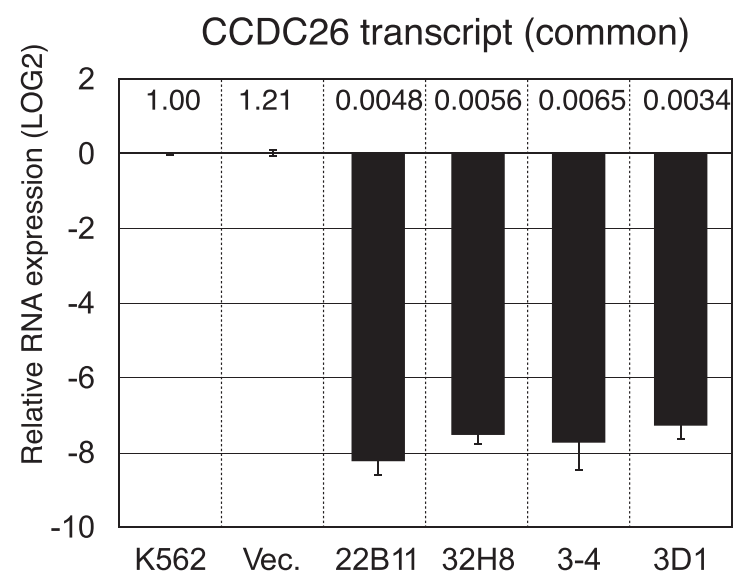

Figure 2 Knockdown of CCDC26 with shRNAs. A. Sequences of shRNAs used in this work. The stems formed in hairpin structures are indicated with bold type. The heads of hairpin structures are indicated by underlined sequence. B. First screen of CCDC26 suppression with shRNA vectors. Clones 22B11, 32H8, 3-4 and 3D1 were used in further investigations (bold type). Clone 32E3 was omitted after a second screening. Targets of the shRNAs are mapped on exon structures (1-2-3-4 and 1a-3-4) of the CCDC26 mRNA variants (see Figure 1B). C. Expression of CCDC26 exon 3-4 in four clones, 3-4, 22B11, 3D1 and 32H8, selected after the second screening. All values were normalized to the expression of CCDC26 in K562 cells.

depletion, respectively. The number of dead cells increased with time after serum depletion for all cell lines; however, the cell death rate in KD clones was lower than that in control cells at 96 as well as 72 hours after serum depletion. The right major peak (labeled "DEAD") corresponding to PI-stained dead cells consists of overlapping double peaks of cells in G1 (open arrow) and G2/M phases (closed arrow). The number of dead cells in the G2/M phase was preferentially decreased in KD cells. This indicates suppression of cell death at a certain point in the cell cycle in KD cells. This result was confirmed by cell-cycle assessment of separated dead and live cells permeabilized and stained with PI. Essentially no difference in distribution of cell cycle-phase was observed between KD and non-KD cells in separated live cells, whereas there was a significant shift in distribution from G1 to $S / G 2 / M$ in dead cells (Additional file 3: Figure $\mathrm{S} 3 \mathrm{~A})$. The rate of cell death for cells grown in $0.1 \%$ FBSor non-FBS-containing medium was also measured by staining with trypan blue. Under each condition, essentially the same result was obtained as above; less cell death was observed in KD clones compared with that in non-KD cells after serum starvation for 72 hours or more (Additional file 3: Figure S3B). 


\section{A}

\begin{tabular}{|c|c|c|c|c|c|}
\hline \multirow{2}{*}{$\frac{128 i^{8 \mathrm{M}}}{M Y C}$} & $129.1 \mathrm{M}$ & $130 \cdot{ }^{3} \mathrm{M}$ & $130.4 \mathrm{M}$ & $130.6 \mathrm{M}$ & $130.7 \mathrm{M}$ \\
\hline & PVT1 & \multirow[t]{2}{*}{ OC728724 } & \multicolumn{2}{|l|}{ CCDC26-short } & hAK015428 \\
\hline & & & \multicolumn{2}{|l|}{ CCDC26-long } & \\
\hline & Location in chromosome 8 & Gene & Accession \# & Property & \\
\hline & $128,748,315-128,753,680$ & $M Y C$ & NM_002467 & Oncogene & \\
\hline & $128,902,874-129,113,499$ & PVT1 & NR_003367 & IncRNA & \\
\hline & $130,228,713-130,253,486$ & LOC728724 & NR_033916 & IncRNA & \\
\hline & $\begin{array}{l}130,363,940-130,692,485 \\
130,363,940-130,587,264\end{array}$ & $C C D C 26$ & $\begin{array}{l}\text { NR_130917 } \\
\text { NR_130918 }\end{array}$ & IncRNA & \\
\hline & $130,705,090-130,705,970 ?$ & hAK015428 & Not Available & IncRNA? & \\
\hline & $130,760,442-130,799,134$ & GSDMC & NM 031415 & Oncogene? & \\
\hline
\end{tabular}

$\mathrm{B}$

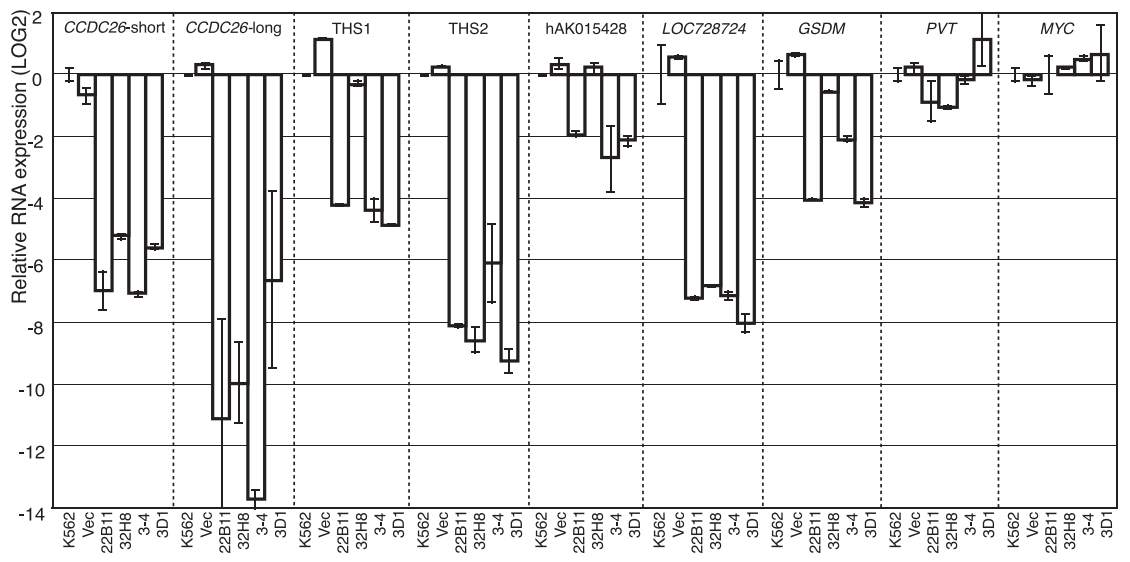

C
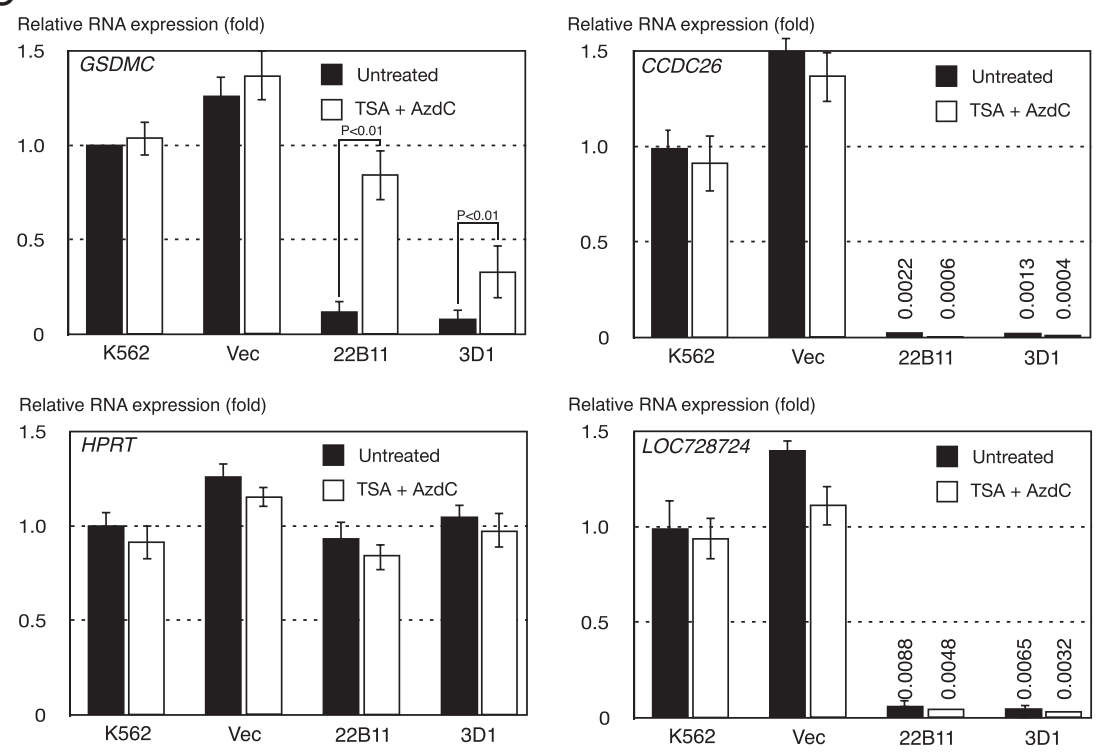

Figure $\mathbf{3}$ (See legend on next page.) 
(See figure on previous page.)

Figure 3 Silencing of the CCDC26 locus in KD clones. A: A map of chromosomal region 8q24 in the vicinity of CCDC26 (128,800,000-130,800,000; sequence numbering is according to the human genome assembly, GRCh37/hg19). Exon-intron structures are not shown. Arrows indicate the direction of transcription. Location and gene annotation are summarized in the table below. B: Expression of CCDC26-short, CCDC26-long, LOC728724, GSDMC, THS1, THS2, human AK015428 homolog (hAK015428), PVTC1 and MYC. Graphs are shown in the log2 scale. C: Treatment with trichostatin A (TSA) and 5-aza-2'-deoxycytidine (AzdC) prevented the suppression of GSDMC but not CCDC26. Open and filled boxes indicate with or without TSA + AzdC, respectively.

\section{Identification of genes that are differentially expressed between CCDC26-KD and non-KD cells}

To comprehensively investigate differences of gene expression between KD and non-KD cells, we carried out DNA microarray analysis with RNA purified from nontransfected K562 cells, vector-transformed cells, and KD clones, 3-4 and 22B11 (Figure 5A). Detailed raw results are presented in Additional file 4: Table S1. We extracted 117 genes that showed a 2-fold or greater change in expression level in both KD clones compared with the control cells (Figure 5B and Additional file 5: Table S2). A heat map to visualize their expression is shown in Additional file 6: Figure S4A. Up- or down-regulation of 109 out of 117 genes was detected in both KD cell lines, indicating a consistency of altered gene expression in CCDC26-KD cells ( $\mathrm{P}=1.24 \mathrm{E}-20$, chi-square test for the categorical data in Figure $5 \mathrm{C}$ ). We chose several most highly differentially expressed candidates for further investigation in the additional KD clones, 3D1 and 32H8, and identified KIT, CD24 and PASD1 to be significantly activated in all KD clones compared with non-KD clones (Figure 5D upper panel). At the same time, MS4A3, SAMSN1 and MS4A4 were suppressed in all KD clones (Figure 5D lower panel). Among the six activated and suppressed genes, KIT was the strongest candidate to be a target of CCDC26 because KIT is known to be frequently mutated in AML [23]. Moreover, pathway analysis revealed that $K I T, C D 24$ and $M S 4 A 4$ form regulatory linkages involving other genes as mediators (Additional file 6: Figure S4B) with KIT having a central role in the regulatory network (Additional file 7: Table S3). For confirmation, we quantified other genes frequently altered in AML, including TET2, IDH1, IDH2, DNMT3A, ASXL1, EZH-2, MLL, RUNX, CBFB and TCF3 [33], but we observed no consistent activation or repression of any of these genes in KD cells (Additional file 8: Figure S5).

\section{Differential KIT protein levels between CCDC26-KD and non-KD cells}

The abundance of KIT protein was confirmed by western blot analysis (Figure 6A). The major band of $145 \mathrm{kD}$, corresponding to the membrane bound form of KIT, was observed in all cell lines. The amount of KIT protein was increased in all KD cells compared with that in non-KD cells, in which a weak KIT signal was observed.
Further evidence for enhanced KIT levels was obtained by immunocytochemistry (Figure 6B). In 3-4 and 22B11 KD cells, KIT was concentrated at the plasma membrane and diffusely distributed in the cytoplasm. No signal was detected in nuclei. These observations confirmed the normal localization of KIT in KD cells.

\section{ISCK03, a tyrosine kinase inhibitor specific to KIT, prevents survival of CCDC26-KD cells under low-serum conditions}

To further investigate the influence of KIT on KD cells, we treated KD cells with ISCK03, a drug that specifically inhibits KIT activity [34]. All treated cells exhibited sensitivity to ISCK03 in a dose-dependent manner (Figure 7A). After ISCK03 treatment, the survival of KD cells was suppressed to the same level as that of non-KD cells. Conversely, ISCK03 treatment had limited effects on the growth of control K562 and KD clone 3-4 cells under high-serum concentration conditions (Figure 7B). Treatment with imatinib, another tyrosine kinase inhibitor specific to ABL but not to KIT, completely abolished the growth of both control K562 and KD cells (Figure 7B). These drugs produced similar growth effects in both control K562 and KD clone 3-4 cells in 10\% FBS-containing medium.

\section{Discussion}

We found several regions in the CCDC26 locus from which transcripts are produced. These transcripts may be independently transcribed or processed from CCDC26 introns that have been spliced out of its precursor mRNA. The transcripts accumulate in K562 cells but, at present, it is difficult to determine which products are functional among the mature mRNA and intronic CCDC26 transcripts [35]. However, accumulation of mature $C C D C 26$ products in the nucleus suggests a functional role [36,37].

An shRNA usually suppresses its target gene by post-transcriptional gene suppression (PTGS), which includes RNA degradation via the RNA-induced silencing complex (RISC). But in some cases, transcriptional gene suppression (TGS) can take place via the RNA-induced transcriptional silencing complex (RITS) $[38,39]$. In this study, shRNA-mediated PTGS does not account for the suppression of the majority of CCDC26 transcripts in KD strains (22B11, 32H8, 3-4 


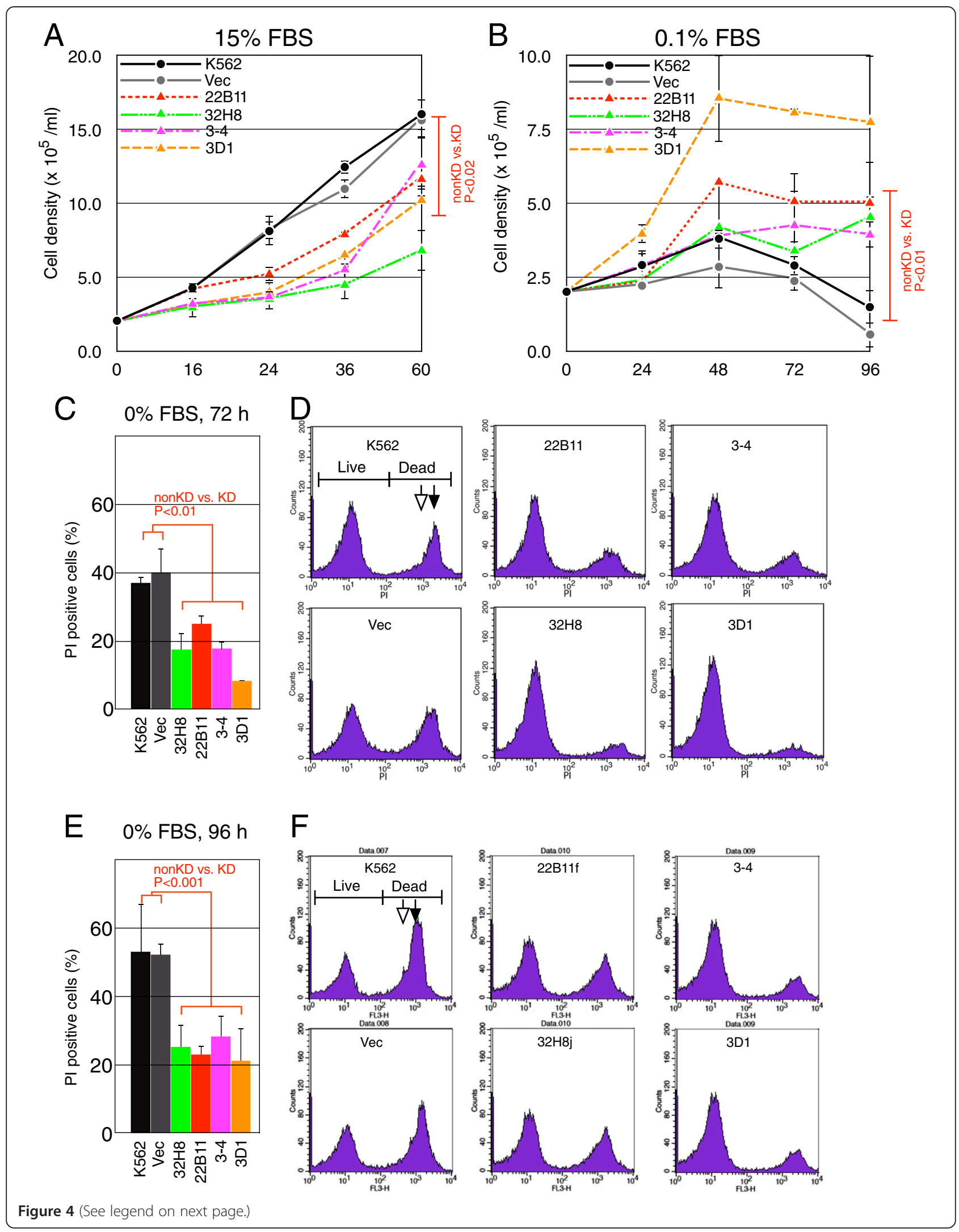


(See figure on previous page.)

Figure 4 CCDC26-KD clones in culture medium containing high or low serum. Growth of CCDC26-KD clones in culture medium containing 15\% (A) or $0.1 \%$ FBS (B). The results show the mean of three or four independent experiments. P values for difference between non-KD (K562 and Vec, GER vector transformed) and KD (22B11, 32H8, 3-4 and 3D1) groups are shown. C: Number of dead cells after serum depletion measured by PI staining and flow cytometry. The results indicated the average of two independent experiments. P values for differences between non-KD and KD groups are shown. D: An example of flow cytometry analysis of cells 72 hours after serum depletion.

and 3D1); partial TGS may have occurred in $32 \mathrm{H} 8$ cells because the THS1 transcript was not suppressed in these cells, as shown in Figure 2B. A straightforward explanation in this case is TGS. Moreover, the chromatin range over which TGS occurs is somewhat different among the CCDC26-KD clones and $1.0 \mu \mathrm{M}$ TSA and $1.0 \mu \mathrm{M}$ AzdC partially prevented the silencing (Figure 3C). Release from silencing by TSA and AzdC was observed at genes located on the borders of the suppressed chromosomal region. This suggests that TGS of these genes by epigenetic mechanisms is accompanied by repressive chromatin modification in the CCDC26-KD clones. In contrast, CCDC26 itself and the adjacent gene, $L O C 728724$, remained silent even after treatment with TSA and AzdC (Figure 3C), indicating that TGS of these genes occurs via a different mechanism.

All the KD clones showed lower growth rates than non-KD control $\mathrm{K} 562$ cells. It seems likely that CCDC26 acts as an oncogene to control cell proliferation, either directly or indirectly. Paradoxically, however, the KD clones proliferated more rapidly in low serum conditions compared with non-KD cells. Additionally, the KD clones survived for longer under conditions of very low or no serum compared with non-KD control cells, which died relatively rapidly under these conditions. This observation indicates that suppression of $C C D C 26$ enables leukemia cells to survive and proliferate despite a severe shortage of growth factors.

DNA microarray and quantitative PCR analysis revealed that the expression of several genes was changed in KD clones. Among them, activation of KIT is especially interesting because this gene is over-expressed in many AML patients. Of note, however, activation of KIT protein in KD cells seemed to be stochastic in spite of their monoclonal origin (Figure 6B). It is likely that there are cells that never express CCDC26 and cells that express more than one molecule, because the number of CCDC26 transcripts in knockdown cells was calculated at less than one per cell, but the transcript was still detected. This might explain the heterogeneous expression of KIT protein in KD cells, although further investigation is needed to resolve this point. Although the existence of KIT-positive cells per se is not a prognostic factor, point mutations in KIT that cause enhanced tyrosine kinase activity are frequently accompanied by chromosomal translocation $t(8 ; 21)$ in adult
AML, which results in poor prognosis [40]. Other genes, including CD24 (a sialoglycoprotein expressed on mature granulocytes and B cells), PASD1 (a transcription factor expressed in diffuse large B-cell lymphoma), MS4A3 (a hematopoietic cell-specific membrane protein), SAMSN1 (a protein with an SH3 domain and nuclear localization signals) and MS4A4 (from the same family as MS4A3) are also interesting because of their involvement with tumors but their relationships to myeloid leukemia are not clear. Nevertheless, we cannot exclude the possibility that CCDC26 regulates cell proliferation or other properties of cells through some of these genes. Overall, we suggest that this ncRNA has novel, previously unknown roles in cellular function. At present, a regulatory function of CCDC26 has been shown in only a single cell line, K562. Despite our efforts, we have not been successful in suppressing the CCDC26 transcripts by RNA interference to sufficient levels in cell lines other than K562 for unknown reasons so far (unpublished results). Further study with different approaches including genome editing might be required to confirm its function.

Although CCDC26 is a low-burden amplified gene expressed in some leukemia cells, amplification occurs partially and does not extend across the whole gene in most cases. This makes it difficult to know whether partial amplification of the gene results in enhancement or loss of its original function. KIT is a well-known oncogene; therefore, if over-expression of the incomplete CCDC26 RNA masks KIT function, our findings are consistent with $C C D C 26$ suppressing some oncogene(s). However, further investigation is required to fully understand this relationship.

LSCs with CD34+ and CD38- surface markers are considered to be a cause of AML recurrence because they have the potential to survive in niche sites that escape the influence of drugs [41]. CCDC26-KD cells might share some properties with LSCs, including relatively slow growth and the ability to survive under certain conditions, such as a shortage of growth factors. Constitutive activation of KIT might contribute to survival of these cells by an autocrine mechanism involving stem cell factor, a ligand for KIT [42]. Although LSCs are usually negative for KIT in de novo AML [43], the existence of KIT-positive LSCs is related to an increased tendency of pediatric AML recurrence after chemotherapy. This can arise from constitutive activation of KIT protein [44]. 
A
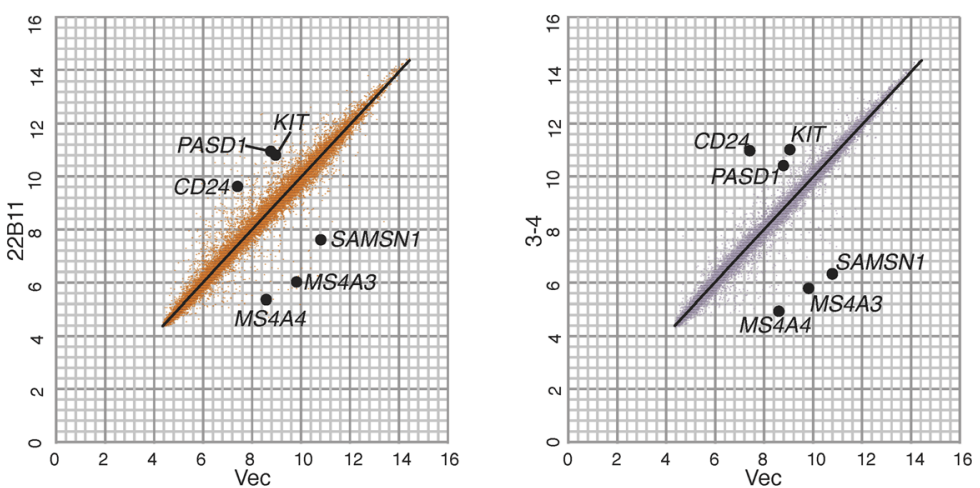

B

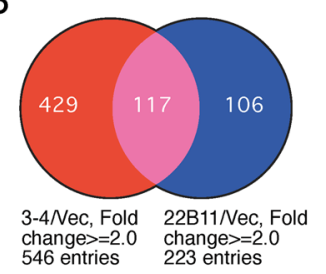

C

\begin{tabular}{|c|c|c|c|}
\hline 22B11 $^{3-4}$ & up & down & total \\
\hline up & 41 & 1 & 42 \\
\hline down & 7 & 68 & 75 \\
\hline total & 48 & 69 & 117 \\
\hline
\end{tabular}

D
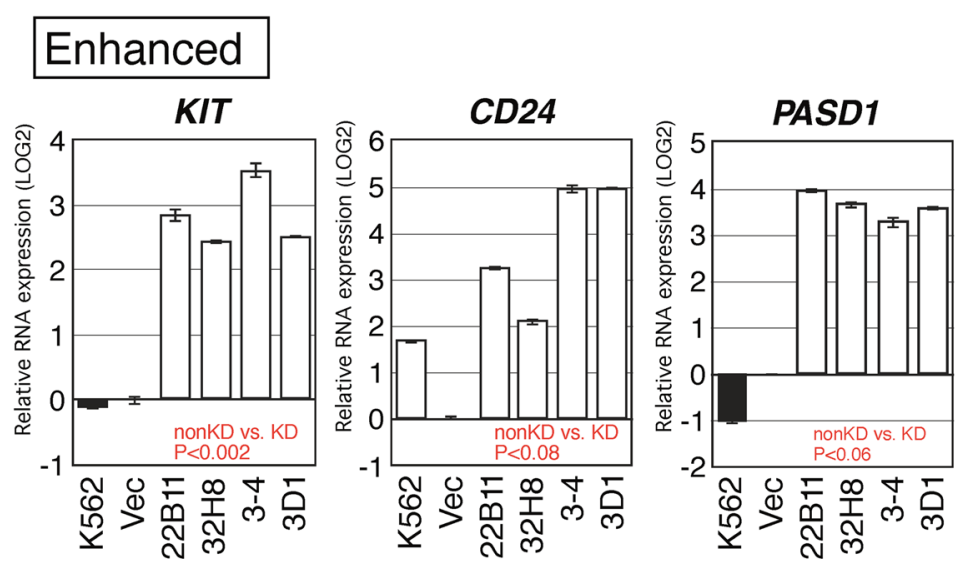

\section{Repressed}

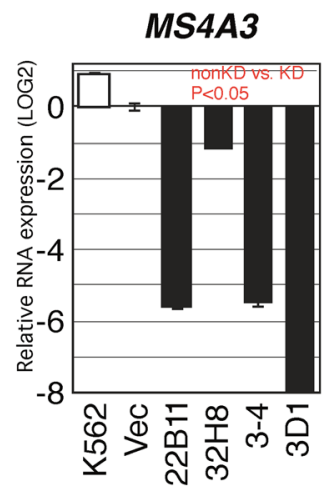

SAMSN1

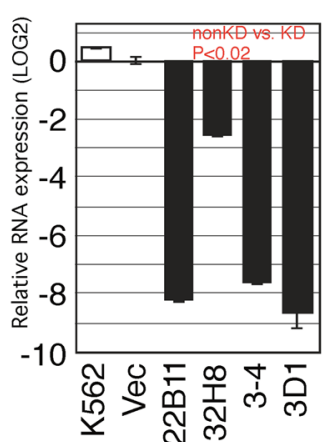

MS4A4

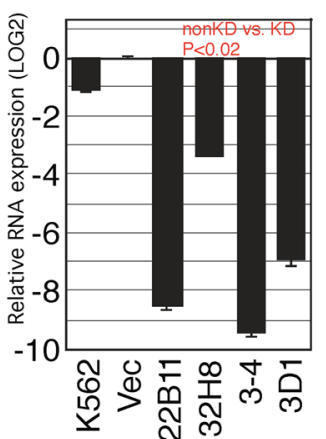

Figure $\mathbf{5}$ (See legend on next page.) 
(See figure on previous page.)

Figure $\mathbf{5}$ Identification of differentially expressed genes between KD and non-KD cells. A: Gene expression levels for KD (22B11 and 3-4) vs. non-KD (Vec: transformed with the empty vector). The six genes in (D) are indicated. B: Genes whose expression differed by 2 -fold or more between KD and non-KD (Vec.) cells. For 3-4 and 22B11 clones, 429 and 106 genes show altered expression, respectively. Among these genes, 117 showed common differential expression between 3-4 and 22B11 clones. C: A cross table of the 117 genes categorized into up or down regulation in each clone. D: Expression was enhanced for three genes (KIT, CD24, PASD1) and repressed for three genes (MS4A3, SAMSN1, MS4A4) in CCDC26-KD cells. The values were normalized against vector-transformed cells and are shown in the log2 scale. Open and filled boxes indicate enhanced and repressed expression, respectively.

\section{Conclusions}

CCDC26 is thought to transcriptionally regulate a set of genes as well as many lncRNAs [45,46]. The collapse of this regulation might alter the properties of myeloid leukemia, possibly leading to disease progression. Whole or partial amplification of the CCDC26 locus is associated with pediatric AML and double minute chromosomepositive AML [26,29]. Abnormal CCDC26 RNA structure could modulate the regulation of KIT to induce undesired enhanced expression. Leukemia characterized by mutation of $C C D C 26$ might be effectively treated by KIT-targeted therapy.

\section{Methods \\ Cell lines}

HL-60 cells are described elsewhere [47,48]. K562 and other cells were obtained from ATCC. All cells were maintained in RPMI 1640 medium supplemented with $10 \% \mathrm{FBS}, 100 \mathrm{U} / \mathrm{ml}$ penicillin, $100 \mathrm{U} / \mathrm{ml}$ streptomycin at $37^{\circ} \mathrm{C}$ in a humidified incubator with a $5 \% \mathrm{CO}_{2}$ atmosphere. KD strains derived from $\mathrm{K} 562$ were maintained

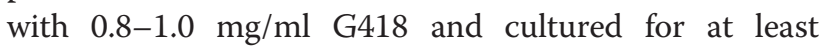
12 hours in fresh medium without G418 prior to use in experiments. Cells were counted with a hemocytometer after staining with $0.25 \%$ trypan blue. Dead cells were stained blue and live cells excluded the dye. TSA (Sigma-Aldrich, St. Louis, MO, USA) was dissolved in dimethyl sulfoxide (DMSO) at a concentration of $5 \mathrm{mM}$. The $5 \mathrm{mM}$ TSA solution was diluted 1/5000 in culture medium. AzdC (Sigma-Aldrich) was dissolved in water and added directly to culture medium. Growth of $\mathrm{K} 562$ cells was inhibited by $40-60 \%$ in media with $1.0 \mu \mathrm{M}$ TSA and $1.0 \mu \mathrm{M}$ AzdC. Equivalent concentrations of DMSO were added to control cells without TSA and AzdC.

\section{Plasmids}

The shRNA expression vector, pGER, is a derivative of the pGE-1 GeneEraser plasmid purchased from Stratagene (La Jolla, CA, USA). The original SV40 virus early gene promoter of pGE-1 that drives the $\mathrm{G} 418$ resistance marker gene was substituted with the Rous sarcoma virus (RSV) promoter, which is more suitable for leukemia cells. In brief, a 580 bp RSV promoter isolated from pRSV.5(neo) (GenBank: M83237.1) by digestion with
HindIII and NdeI was blunt-end ligated to a $2.6 \mathrm{~kb}$ fragment purified from pGE-1 partially digested with StuI and PvuII.

\section{Isolation of KD clones}

Transfection to K562 cells was performed using DimrieC (Invitrogen, Carlsbad, CA, USA) according to the manufacturer's instructions using $0.5 \mu \mathrm{g}$ of plasmid DNA per $10^{5}$ cells in $500 \mu \mathrm{l}$ medium. Cells were plated in methylcellulose based-matrix (ClonaCell; Stem Cell Technologies, Vancouver, Canada) on six-well culture plates to form colonies and were selected with 1.6 $\mathrm{mg} / \mathrm{ml}$ G418 from 48 hours after transfection. Visible colonies were isolated using a Pipetman under microscopic observation after selection for 6-8 days. Cells were transferred to 96-well plates and were maintained to proliferate in culture medium containing $1.6 \mathrm{mg} / \mathrm{ml} \mathrm{G418}$. For the first screening, $10^{4}$ cells were used for RNA preparation. Clones selected in first screening were subcloned by the limiting dilution method and propagated. RNA was then prepared for a second screening. Colonies of empty pGER transformants were pooled and used as control non-KD cells.

\section{Quantification of RNA}

RNA for quantification was prepared using RNAiso Plus (Takara Bio, Otsu, Japan) according to the manufacturer's instructions. Synthesis of cDNA was performed using ReverTra Ace qPCR RT Master Mix with gDNA Remover (Toyobo, Osaka, Japan) according to the manufacturer's instructions. Quantification of cDNAs using primer sets specific to each gene or transcript was performed with the LightCycler system (Roche Diagnostics, Indianapolis, IN, USA). To measure the absolute number of cDNA molecules, known concentrations of PCR product were used to generate a calibration curve. Total RNA in a single cell was estimated at $10 \mathrm{pg}$ ( $1 \mathrm{mg}$ for $10^{8}$ cells). In other quantification, we used HPRT gene expression as an internal standard. Primer sets used in PCR experiments are listed in Additional file 9: Table S4.

\section{Isolation of nuclei}

Isolation of nuclei was performed according to Spector et al. [49] with slight modification. In brief, $1 \times 10^{7}$ cells were washed once with $\mathrm{PBS}(-)$ and suspended in $0.5 \mathrm{ml}$ 


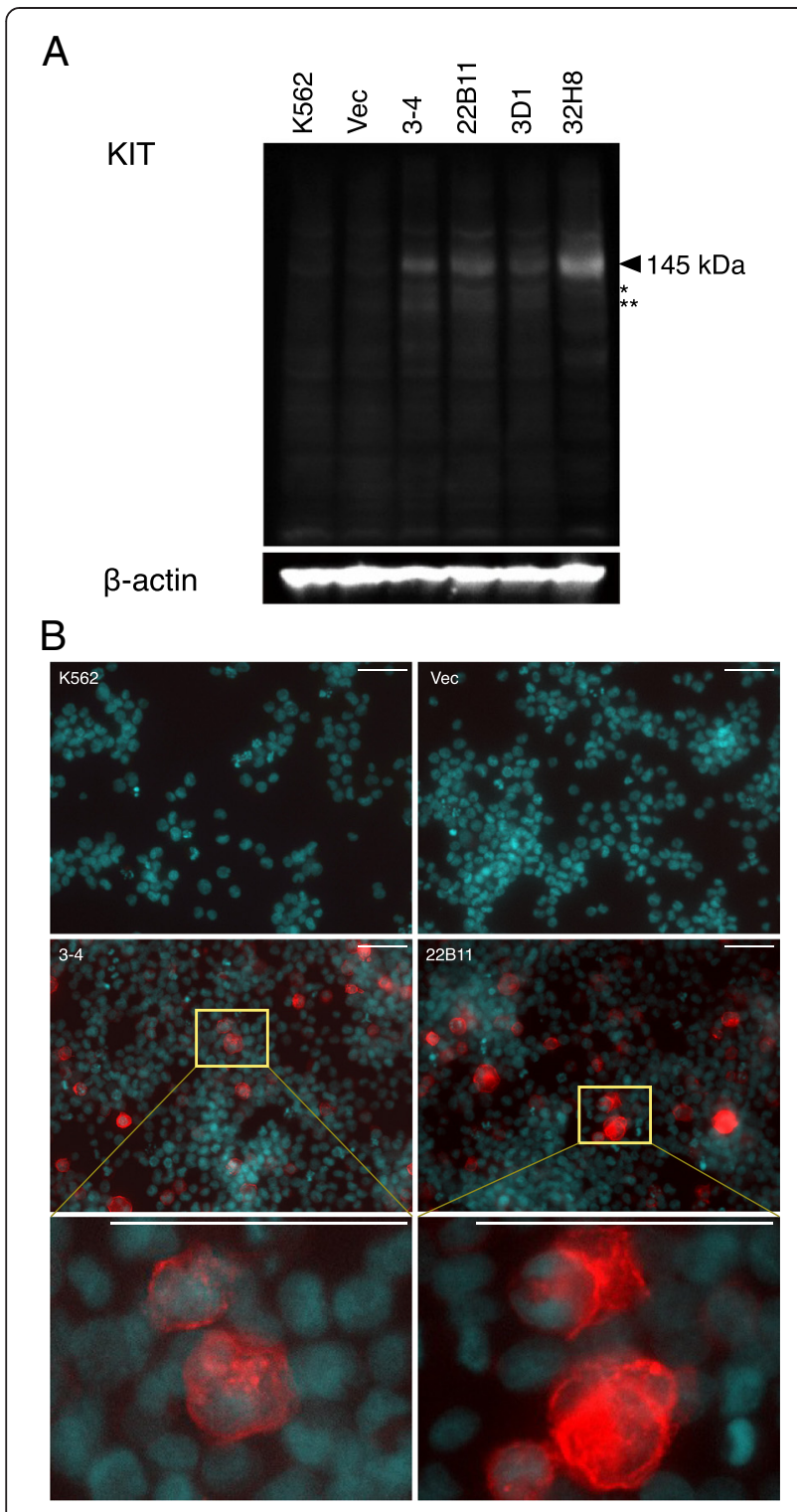

Figure 6 Detecting differential levels of KIT protein. A: Western blot analysis for KIT protein in K562, Vec (GER vector transformed), 3-4, 22B11, 3D1 and 32H8 cells. Arrow and asterisks indicate $145 \mathrm{kD}$ membrane bound KIT (arrow), a $120 \mathrm{kD}$ form of KIT (*) and a $100 \mathrm{kD}$ $\left.{ }^{(* *}\right)$ soluble form of KIT. The same blot reprobed with an antibody for beta actin as a loading control is shown below.

B: Immunocytochemistry for KIT in K562, Vec and KD clones (3-4 and 22B11). Nuclei are counter-stained with Hoechst 33342 (blue). KIT protein is stained red. Higher magnifications for 3-4 and 22B11 are also shown. Scale bars, $50 \mu \mathrm{m}$.

of buffer A (10 mM Hepes-KOH [pH 8.0], $10 \mathrm{mM} \mathrm{KCl}$, $1.5 \mathrm{mM} \mathrm{MgCl}, 1 \mathrm{mM}$ dithiothreitol (DTT), $0.5 \mathrm{mM}$ phenylmethylsulfonyl fluoride (PMSF), $0.5 \mathrm{U} / \mu \mathrm{l}$ RNase inhibitor). Cells were incubated on ice for $10 \mathrm{~min}$ and then lysed in a Dounce homogenizer. Crude nuclei were collected by centrifugation at $1,300 \times \mathrm{g}$ for $5 \mathrm{~min}$ and resuspended in $0.5 \mathrm{ml}$ buffer B $(0.25 \mathrm{M}$ sucrose, $10 \mathrm{mM}$
Tris- $\mathrm{HCl}$ [pH 7.9], $5 \mathrm{mM} \mathrm{MgCl}_{2}, 1 \mathrm{mM}$ DTT, $0.5 \mathrm{mM}$ PMSF). Suspended crude nuclei were centrifuged on a cushion of $0.4 \mathrm{ml}$ buffer $\mathrm{C}$ (1.2 $\mathrm{M}$ sucrose, $10 \mathrm{mM}$ Tris$\mathrm{HCl}$ [pH 7.9], $5 \mathrm{mM} \mathrm{MgCl}_{2}, 0.1 \%$ TritonX-100, $1 \mathrm{mM}$ DTT, $0.5 \mathrm{mM} \mathrm{PMSF}$ ) at $10,000 \times \mathrm{g}$ for $30 \mathrm{~min}$. Precipitated nuclei were resuspended in $0.5 \mathrm{ml}$ buffer $\mathrm{B}$ and again centrifuged on a cushion of $0.4 \mathrm{ml}$ buffer $\mathrm{C}$. All procedures were carried out at $0-4^{\circ} \mathrm{C}$. The precipitated nuclear fraction was used directly for RNA preparation using RNAiso plus (Takara Bio).

\section{DNA microarray analysis}

Total RNA from each clone was prepared using RNAeasy (Qiagen, Venlo, Netherlands) according to the manufacturer's instructions. Using an Ambion WT Expression Kit (Ambion, Foster City, CA, USA) and a WT Terminal Labeling Kit (Affymetrix, Santa Clara, CA, USA), $250 \mathrm{ng}$ of RNA was converted to biotin-labeled single stranded cDNA. Fifteen micrograms of single stranded DNA was hybridized to a Human Gene 1.0 ST Array (Affymetrix), followed by staining and washing. Scanning was carried out using a GeneChip Scanner 3000 7G (Affymetrix).

\section{PI-staining and FACS analysis of dead cells}

Cells were washed with PBS and stained in buffer containing 3\% FBS, $0.05 \% \mathrm{NaN}_{3}$ and $2 \mu \mathrm{g} / \mathrm{ml}$ propidium iodide (Sigma-Aldrich) for $15 \mathrm{~min}$ at room temperature and analyzed on a FACSCalibur flow cytometer (Beckton Dickinson, Franklin Lakes, NJ, USA).

\section{Western blot analysis}

K562 cells, pGER vector-transformed K562 cells (Vec) and four strains of $\mathrm{K} 562-\mathrm{KD}$ cells were cultured at $37^{\circ} \mathrm{C}$ in a $5 \% \mathrm{CO}_{2}$ atmosphere until the logarithmic growth phase. $2 \times 10^{6}$ cells were lysed by sonication in $0.2 \mathrm{ml}$ Laemmli buffer (125 mM Tris- $\mathrm{HCl}, \mathrm{pH}$ 6.8, 4\% sodium dodecyl sulfate (SDS), $100 \mathrm{mM}$ dithiothreitol). Ten microliters of protein extract, equivalent to $1 \times 10^{5}$ cells, were separated on a SDS polyacrylamide gel electrophoresis pre-made 5-20\% gradient gel (Wako Pure Chemical Industries, Osaka, Japan) and then transferred to polyvinylidene fluoride membrane (Immobilon-P Transfer Membrane; Millipore, Billerica, MA, USA). The blot was blocked in 7\% BlockAce (DS Pharma Biomedical, Osaka Japan) at $4^{\circ} \mathrm{C}$ for 2 nights to suppress nonspecific signal and then incubated in CanGetSignal solution 1 (Toyobo) with $1 / 1500$ diluted mouse monoclonal anti-KIT antibody (\#Ab-81; Cell Signaling Technology, Danvers, MA, USA) and mouse monoclonal anti-beta-actin antibody (\#E1C605; Enogene, New York, NY, USA) (to determine loading). After washing, the blot was incubated in CanGetSignal solution 2 (Toyobo) with anti-mouse IgG secondary antibody conjugated with horseradish 


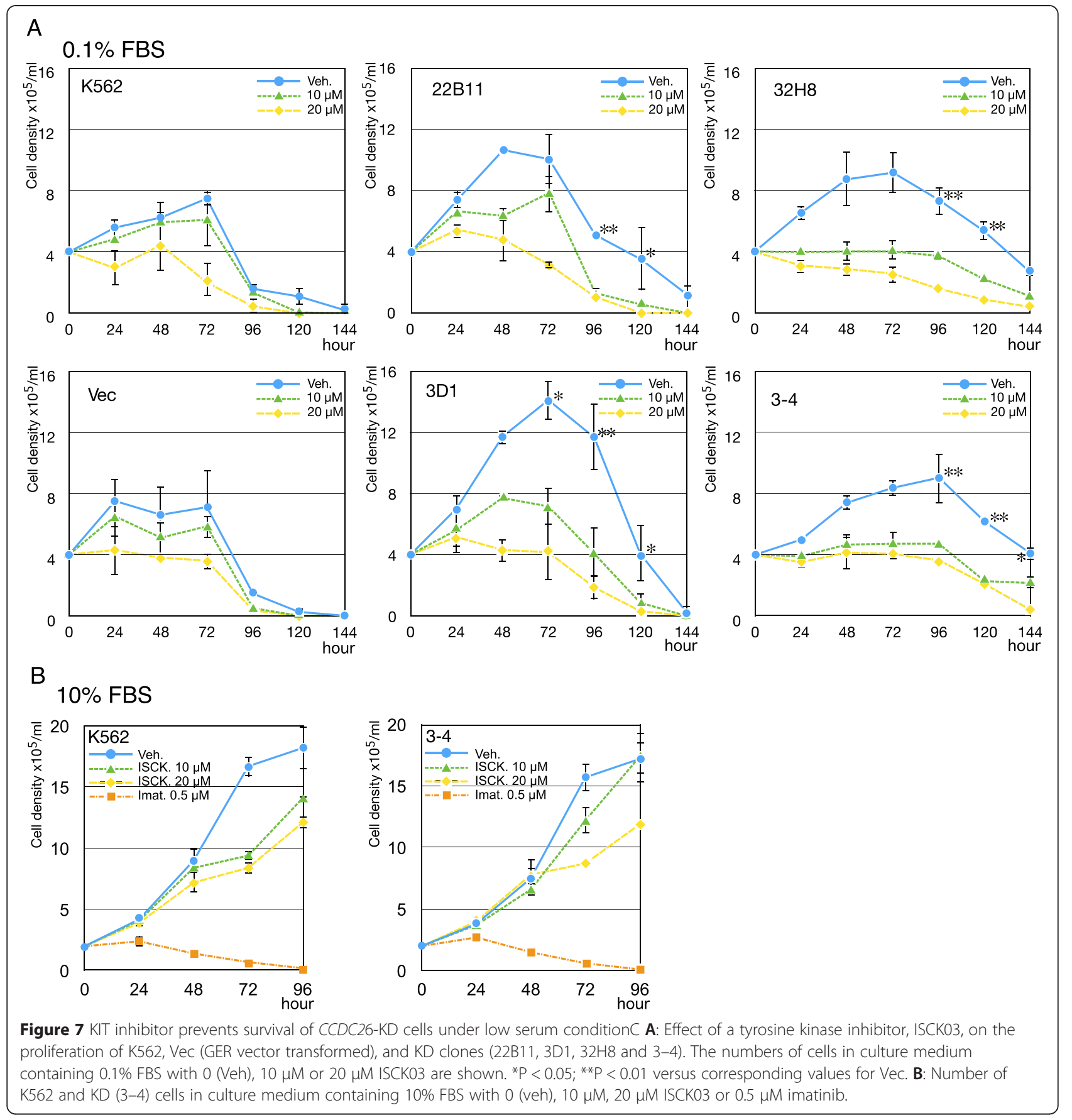

peroxidase (KPL, Gaithersburg, MD, USA) and then visualized with Chemi-lumi One Super (Nakalai Tesque, Kyoto, Japan). Images were recorded with a Lumino imaging analyzer FAS-1000 (Toyobo).

\section{Immunocytochemistry}

Cells were suspended and fixed in PBS containing 4\% paraformaldehyde for $15 \mathrm{~min}$ at room temperature. After washing with PBS, cells were suspended in $0.2 \%$ Triton/ PBS and incubated for $10 \mathrm{~min}$ at room temperature.
After washing with PBS, cells were spread on glass slides using the Thin-layer cell preparation system Cytospin 4 (Thermo-Fisher Scientific, Waltham, MA, USA). Cells were then incubated with $2 \%$ BSA in PBS to block nonspecific signals followed by incubation with $1 / 100$ diluted mouse monoclonal anti-KIT antibody (\#Ab-81; Cell Signaling Technology) in CanGetSignal immunostain solution B (Toyobo) overnight at $44^{\circ} \mathrm{C}$. Alexa Fluor 546 goat anti-mouse IgG (Invitrogen) was used as a secondary antibody. The specimens were counterstained with $1 \mu \mathrm{M}$ 
Hoechst 33428 (AnaSpec, Fremont, CA, USA) and observed under a fluorescence microscope (BA-9000; Keyence, Osaka, Japan).

\section{Additional files}

Additional file 1: Figure $\mathbf{S 1}$. Summary of expression from the CCDC26 locus. Reprinted from the Human Feb. 2009 (GRCh37/hg19) assembly on the UCSC Genome Browser. Scores for K562 cells showing whole cell RNA with polyA, without polyA, cytoplasmic RNA with polyA, without polyA, nuclear RNA with polyA, without polyA, chromatin associated RNA, tri-methylated histone H3K4 and acetylation of histone H3K27.

Additional file 2: Figure S2. Summary for CCDC26 knockdown clones. B: Map of the shRNA vector, pGER. The RSV-promoter (P-RSV) was inserted in place of the original SV40-promoter to drive expression of the neo/kan marker gene in pGE-1. B: An example of detailed expression analysis of KD clones. Values of quantified RNA are shown in the log scale. Averages of clones (AVR) are shown on the right-hand end of each graph.

Additional file 3: Figure S3. Cell death of KD cells in low serum conditions. A: Flow cytometry assessment of cell cycle by PI staining of separated live and dead cells at 96 hours after serum depletion. Separation of live and dead cells was performed using Lympholyte Cell Separation Media CL5015 (Cedarlane, Ontario, Canada). Mode values of PI intensity of the live and dead cells are indicated with arrows. B: Cell death rates in medium containing 0.1 or $0 \%$ serum. The results at 96 and 122 hours are relatively unclear because cell debris increased counting error.

Additional file 4: Table S1. Raw data of the microarray analysis. Additional file 5: Table S2. List of 117 genes with commonly altered expression.

Additional file 6: Figure S4. A: Heat map (Blue color for low expression and red color for high expression) and list for the expression levels of the 117 genes. A detailed list of the 117 genes is also shown in Additional file 5: Table S2. B: Pathway analysis for CD24, KIT and MS4A4. Six genes chosen in Figure 5 were analyzed with Pathway analyzing software, KeyMolnet (KMdata, Tokyo, Japan). Known interactions for transmembrane proteins KIT, CD24 and MS4A4 (red-filled circles) were found. Nuclear and cytoplasmic factors (blue-filled circles) are shown with solid and dashed lines indicating actual binding and regulatory effects, respectively.

Additional file 7: Table S3. GO term analysis performed with Ingenuity Pathway analysis software (Qiagen).

Additional file 8: Figure S5. Expression of genes frequently altered in AML. The representative expression of genes that are frequently altered in AML patients was measured in KD, Vec (GER vector transformed) and KD clones (22B11, 32H8, 3-4 and 3D1).

Additional file 9: Table S4. Primer sets used in this study.

\section{Abbreviations}

AzdC: 5-aza-2'-deoxycytidine; AML: Acute myeloid leukemia; CML: Chronic myeloid leukemia; CNA: Copy number alteration; DNMT: DNA methyltransferase; KD: Knockdown; LSC: Leukemia stem cells; IncRNA: Long noncoding RNA; PTGS: Post-transcriptional gene silencing; PI: Propidium iodide; shRNA: Short hairpin RNA; RSV: Rous sarcoma virus;

TGS: Transcriptional gene silencing; TSA: Trichostatin A.

\section{Competing interests}

The authors declare that they have no competing interests.

\section{Authors' contributions}

RY carried out the cell fractionation study. $\mathrm{HH}$ and $\mathrm{YH}$ prepared samples from cell lines. Al and TY planned and supervised execution of the project. All authors read and approved the final manuscript.

\section{Acknowledgments}

The flow cytometric analysis was carried out at the Center for Gene Science, Natural Science Center for Basic Research and Development (N-BARD), Hiroshima University, and we thank Drs. Nobuo Tanaka and Kenji Kitamura for their assistance. The microarray analysis was carried out at the Analysis Center of Life Science, N-BARD, Hiroshima University, and we thank Ms Nagisa Morihara for excellent support in bioinformatics analysis. We also thank Drs. Tatsuo Nehira, Yasuhiro Ishihara, Tetsuya Nosaka, Shigeru Kakuta and Wataru Fujii for encouraging discussions. This work was supported by JSPS KAKENHI Grant Number 24510277.

\section{Author details}

'Domain of Life Sciences, Graduate School of Integrated Arts and Sciences, Hiroshima University, 1-7-1 Kagamiyama, Higashihiroshima, Hiroshima 739-8521, Japan. ${ }^{2}$ Department of Hematology, Juntendo University School of Medicine, 2-1-1 Hongo, Bunkyo-ku, Tokyo 113-8421, Japan.

Received: 12 December 2014 Accepted: 9 April 2015

Published online: 19 April 2015

\section{References}

1. Alexander RP, Fang G, Rozowsky J, Snyder M, Gerstein MB. Annotating non-coding regions of the genome. Nat Rev Genet. 2010;11:559-71.

2. Brosnan CA, Voinnet O. The long and the short of noncoding RNAs. Curr Opin Cell Biol. 2009;21:416-25.

3. Mattick JS. The genetic signatures of noncoding RNAs. PLoS Genet. 2009;5, e1000459.

4. Zaratiegui M, Irvine DV, Martienssen RA. Noncoding RNAs and gene silencing. Cell. 2007;128:763-76.

5. Liu N, Okamura K, Tyler DM, Phillips MD, Chung WJ, Lai EC. The evolution and functional diversification of animal microRNA genes. Cell Res. 2008:18:985-96,

6. Kutter C, Svoboda P. miRNA, siRNA, piRNA: Knowns of the unknown. RNA Biol. 2008;5:181-8.

7. Vaz C, Ahmad HM, Sharma P, Gupta R, Kumar L, Kulshreshtha R, et al. Analysis of microRNA transcriptome by deep sequencing of small RNA libraries of peripheral blood. BMC Genomics. 2010;11:288.

8. Czech B, Hannon GJ. Small RNA sorting: matchmaking for Argonautes. Nat Rev Genet. 2011:12:19-31.

9. Varol N, Konac E, Gurocak OS, Sozen S. The realm of microRNAs in cancers. Mol Biol Rep. 2011;38:1079-89.

10. Mercer TR, Dinger ME, Mattick JS. Long non-coding RNAs: insights into functions. Nat Rev Genet. 2009:10:155-9.

11. Spizzo R, Almeida MI, Colombatti A, Calin GA. Long non-coding RNAs and cancer: a new frontier of translational research? Oncogene. 2012;31:4577-87.

12. Wilusz JE, Sunwoo H, Spector DL. Long noncoding RNAs: functional surprises from the RNA world. Genes Dev. 2009;23:1494-504.

13. Taft RJ, Pang KC, Mercer TR, Dinger M, Mattick JS. Non-coding RNAs: regulators of disease. J Pathol. 2010;220:126-39.

14. Wapinski O, Chang HY. Long noncoding RNAs and human disease. Trends Cell Biol. 2011;21:354-61.

15. Kelly LM, Gilliland DG. Genetics of myeloid leukemias. Annu Rev Genomics Hum Genet. 2002;3:179-98.

16. Kumar CC. Genetic abnormalities and challenges in the treatment of acute myeloid leukemia. Genes Cancer. 2011;2:95-107.

17. Frohling S, Scholl C, Gilliland DG, Levine RL. Genetics of myeloid malignancies: pathogenetic and clinical implications. J Clin Oncol. 2005;23:6285-95.

18. Harada Y, Harada H. Molecular pathways mediating MDS/AML with focus on AML1/RUNX1 point mutations. J Cell Physiol. 2009;220:16-20.

19. Deininger $M, B u c h d u n g e r ~ E$, Druker BJ. The development of imatinib as a therapeutic agent for chronic myeloid leukemia. Blood. 2005;105:2640-53.

20. McWeeney SK, Pemberton LC, Loriaux MM, Vartanian K, Willis SG, Yochum $\mathrm{G}$, et al. A gene expression signature of CD34+ cells to predict major cytogenetic response in chronic-phase chronic myeloid leukemia patients treated with imatinib. Blood. 2010;115:315-25.

21. Radich JP, Dai H, Mao M, Oehler V, Schelter J, Druker B, et al. Gene expression changes associated with progression and response in chronic myeloid leukemia. Proc Natl Acad Sci U S A. 2006;103:2794-9. 
22. Mrozek K, Radmacher MD, Bloomfield CD, Marcucci G. Molecular signatures in acute myeloid leukemia. Curr Opin Hematol. 2009;16:64-9.

23. Caceres-Cortes JR. Blastic leukaemias (AML): a biologist's view. Cell Biochem Biophys. 2013;66:13-22

24. Huntly BJP, Gilliland DG. Leukaemia stem cells and the evolution of cancer-stem-cell research. Nat Rev Cancer. 2005:5:311-21.

25. Hirano T. Is CCDC26 a Novel Cancer-Associated Long-Chain Non-Coding RNA? In: Siregar Y, editor. Oncogene and Cancer-From Bench to Clinic Rijeka, Croatia: INTECH; 2013. p. 415-34.

26. Radtke I, Mullighan CG, Ishii M, Su X, Cheng J, Ma J, et al. Genomic analysis reveals few genetic alterations in pediatric acute myeloid leukemia. Proc Natl Acad Sci U S A. 2009;106:12944-9.

27. Hirano T, Ike F, Murata T, Obata Y, Utiyama H, Yokoyama KK. Genes encoded within 8 q24 on the amplicon of a large extrachromosomal element are selectively repressed during the terminal differentiation of $\mathrm{HL}-60$ cells. Mutat Res. 2008;640:97-106.

28. Storlazzi CT, Fioretos T, Paulsson K, Strombeck B, Lassen C, Ahlgren T, et al. Identification of a commonly amplified $4.3 \mathrm{Mb}$ region with overexpression of C8FW, but not MYC in MYC-containing double minutes in myeloid malignancies. Hum Mol Genet. 2004;13:1479-85.

29. Storlazzi CT, Fioretos T, Surace C, Lonoce A, Mastrorilli A, Strombeck B, et al. MYC-containing double minutes in hematologic malignancies: evidence in favor of the episome model and exclusion of MYC as the target gene. Hum Mol Genet. 2006;15:933-42.

30. Yin W, Rossin A, Clifford JL, Gronemeyer H. Co-resistance to retinoic acid and TRAIL by insertion mutagenesis into RAM. Oncogene. 2006;25:3735-44.

31. Shete S, Hosking FJ, Robertson LB, Dobbins SE, Sanson M, Malmer B, et al. Genome-wide association study identifies five susceptibility loci for glioma. Nat Genet. 2009;41:899-904.

32. Consortium EP. An integrated encyclopedia of DNA elements in the human genome. Nature. 2012;489:57-74.

33. Shih AH, Abdel-Wahab O, Patel JP, Levine RL. The role of mutations in epigenetic regulators in myeloid malignancies. Nat Rev Cancer. 2012;12:599-612.

34. Na YJ, Baek HS, Ahn SM, Shin HJ, Chang IS, Hwang JS, et al. [4-tbutylphenyl]-N-(4-imidazol-1-yl phenyl)sulfonamide (ISCK03) inhibits SCF/ c-kit signaling in 501 mel human melanoma cells and abolishes melanin production in mice and brownish guinea pigs. Biochem Pharmacol. 2007;74:780-6.

35. Louro R, El-Jundi T, Nakaya HI, Reis EM, Verjovski-Almeida S. Conserved tissue expression signatures of intronic noncoding RNAs transcribed from human and mouse loci. Genomics. 2008;92:18-25.

36. Chen LL, Carmichael GG. Decoding the function of nuclear long noncoding RNAs. Curr Opin Cell Biol. 2010;22:357-64

37. Umlauf $D$, Fraser $P$, Nagano $T$. The role of long non-coding RNAs in chromatin structure and gene regulation: variations on a theme. Biol Chem. 2008:389:323-31.

38. Castel SE, Martienssen RA. RNA interference in the nucleus: roles for small RNAs in transcription, epigenetics and beyond. Nat Rev Genet. 2013;14:100-12.

39. Morris KV, Chan SW, Jacobsen SE, Looney DJ. Small interfering RNA-induced transcriptional gene silencing in human cells. Science. 2004;305:1289-92.

40. Wang YY, Zhao L, Wu CF, Liu P, Shi L, Liang Y, et al. C-KIT mutation cooperates with full-length AML1-ETO to induce acute myeloid leukemia in mice. Proc Natl Acad Sci U S A. 2011:108:2450-5.

41. Ishikawa F, Yoshida S, Saito Y, Hijikata A, Kitamura H, Tanaka S, et al. Chemotherapy-resistant human AML stem cells home to and engraft within the bone-marrow endosteal region. Nat Biotechnol. 2007;25:1315-21.

42. Belloc F, Airiau K, Jeanneteau M, Garcia M, Guerin E, Lippert E, et al. The stem cell factor-c-KIT pathway must be inhibited to enable apoptosis induced by BCR-ABL inhibitors in chronic myelogenous leukemia cells. Leukemia. 2009:23:679-85.

43. Luo L, Han ZC. Leukemia stem cells. Int J Hematol. 2006;84:123-7.

44. Chavez-Gonzalez A, Dorantes-Acosta E, Moreno-Lorenzana D, AlvaradoMoreno A, Arriaga-Pizano L, Mayani H. Expression of CD90, CD96, CD117, and CD123 on different hematopoietic cell populations from pediatric patients with acute myeloid leukemia. Arch Med Res. 2014;45:343-50.

45. Vance KW, Sansom SN, Lee S, Chalei V, Kong L, Cooper SE, et al. The long non-coding RNA Paupar regulates the expression of both local and distal genes. EMBO J. 2014;33:296-311.
46. Di Ruscio A, Ebralidze AK, Benoukraf T, Amabile G, Goff LA, Terragni J, et al. DNMT1-interacting RNAs block gene-specific DNA methylation. Nature. 2013;503:371-6.

47. Haque MM, Hirano T, Itoh N, Utiyama H. Evolution of large extrachromosomal elements in HL-60 cells during culture and the associated phenotype alterations. Biochem Biophys Res Commun. 2001;288:592-6.

48. Haque MM, Hirano T, Nakamura H, Utiyama H. Granulocytic differentiation of $\mathrm{HL}-60$ cells, both spontaneous and drug-induced, might require loss of extrachromosomal DNA encoding a gene(s) not c-MYC. Biochem Biophys Res Commun. 2001;288:586-91.

49. Spector DL, Goldman RD, Leinwand LA. Isolation of Nucleoli in Cells: A laboratory manual, vol. 1: Cold Spring Harbor Lab. Press; 1997.

\section{Submit your next manuscript to BioMed Central and take full advantage of:}

- Convenient online submission

- Thorough peer review

- No space constraints or color figure charges

- Immediate publication on acceptance

- Inclusion in PubMed, CAS, Scopus and Google Scholar

- Research which is freely available for redistribution 